УДК 686.12.056

๑ А. І. Іванко, к.т.н, доцент, С. Л. Панов, к.Т.н, доцент, Р. В. Маржієвський, магістрант, НТУУ «КПІ», Київ, Україна

\title{
КІНЕМАТИЧНІ ТА ДИНАМІЧНІ ПАРАМЕТРИ ПРИСТРОЮ ДЛЯ ОБРІЗУВАННЯ АРКУШЕВОГО МАТЕРІАЛУ
}

У статті представлено результати попередніх кінематичних і динамічних розрахунків конструкції пристрою безупинного обрізування аркушевого матеріалу.

Ключові слова: пристрій для обрізування аркушевого матеріалу, кривошипно-кулісний механізм, кінематичний аналіз, динамічний аналіз, силовий розрахунок.

\section{Постановка проблеми}

Питання підвищення продуктивності роботи потокової лінії особливо для модуля обрізування корінця напівфабрикату $є$ актуальним. Проблема якості поверхні зрізу та мінімізації споживаної потужності приводу може бути вирішена за рахунок модернізації відомої конструкції пристрою обрізування, або створення принципово нової [1-5].

\section{Аналіз попередніх досліджень}

Новий спосіб безупинного обрізування аркушевого матеріалу та пристрій для його реалізації складається з транспортувальної системи, механізму притиску та механізму ножа [6, 7]. Напівфабрикат попереднім притиском фіксується в рухомій каретці і передається в зону обрізування.

Необхідне зусилля притиску забезпечується притискними пружинами. Зсув під час контакту головного притиску і напівфабрикату компенсується гідравлічними циліндрами закріплени- ми в рамі. Відповідно така конструкція механізму дозволяє виконувати процес різання під час руху каретки 3 напівфабрикатами.

\section{Мета роботи}

Метою роботи $€$ представлення результатів кінематичного та динамічного аналізу комбінованого, кривошипно-кулісного механізму для обрізування аркушевого матеріалу. Аналіз процесу обрізування аркушевого матеріалу в потоковій лінії та взаємодія виконавчих елементів механізму.

\section{Результати проведених досліджень}

Запропонований на кафедрі МАПВ ВПІ механізм (патент № 80303B26D1/00) кривошипно-кулісного типу дає можливість суттєво покращити технічні характеристики брошурувально-палітурного обладнання.

До кінематичних характеристик механізму належать: координати та траєкторії руху характерних точок; узагальнені коор- 


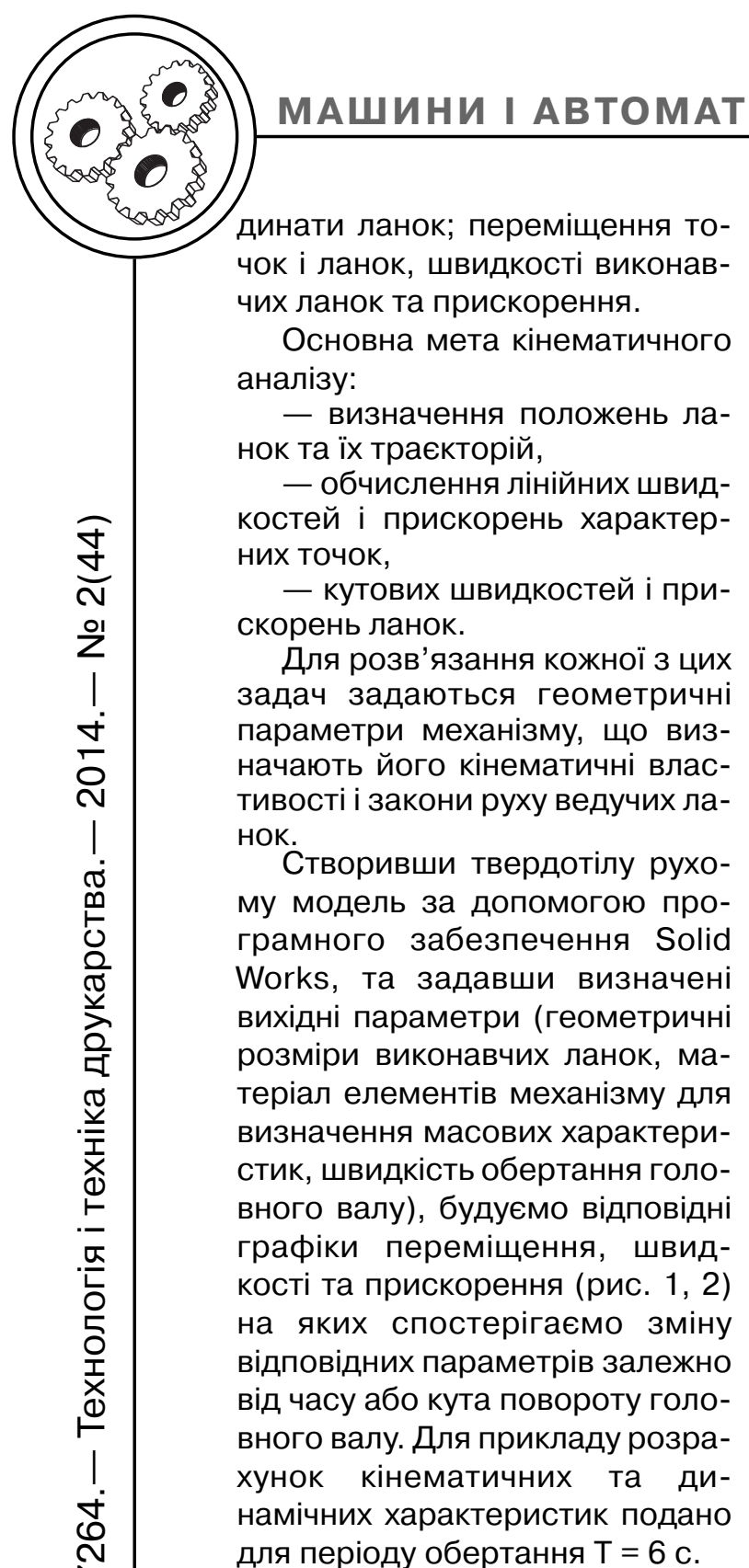

Швидкість руху ножа $\mathrm{V}_{\mathrm{H}}$ (рис. 1) змінюється залежно від його положення відносно осі обертання. Так при крайньому верхньому положенні (зворотному ході) ножа його лінійна швидкість буде максимальна i становитиме $\mathrm{V}_{\text {н.max }}=307 \mathrm{~mm} / \mathrm{c}$. При цьому швидкість балки головного притиску $V_{\text {п }}$ (рис. 2) в даному положенні механізму досягає свого максимуму $\mathrm{V}_{\text {п. } \max }=$
$=1785 \mathrm{~mm} / \mathrm{c}$ (відносно осі Х).Тобто, головний притиск рухається паралельно з кареткою. Відповідно в цей момент прискорення ножа та балки притиску буде дорівнювати нулю.

За вибраними кінематичними параметрами ніж дорізуе останні аркуші у стосі на швидкості $\mathrm{V}_{\mathrm{H}}=100 \mathrm{~mm} / \mathrm{c}$ (відносно осі Ү). Для випадку, коли ніж врізається у напівфабрикат спостерігаємо зміну швидкості головного притиску у межах $\mathrm{V}_{\text {п }}=$ $=240 \ldots 255 \mathrm{~mm} / \mathrm{c}$. Така зміна швидкості не суттєво впливатиме на силу притиску і забезпечуватиме постійний i рівномірний притиск напівфабрикату під час транспортування і різання.

Завданням силового розрахунку є визначення сил, що діють на ланки механізмів, реакцій в кінематичних парах i величину зрівноважувальної сили.

До силового розрахунку відносимо наступні етапи:

- Побудова динамічної схеми механізму.

- Визначаємо сили тяжіння ланок механізму G;

- Визначаємо моменти інерції $J_{S}$ сили інерції $P_{\mathrm{i}}$ i моменти сил інерції $\mathrm{M}_{\mathrm{i}}$ для всіх ланок механізму.

- Силовий розрахунок першої та другої приєднаної групи Ассура.

- Силовий розрахунок ведучої ланки.

Для аналізу навантажень в середовищі SolidWorks, задається сила, що діє на виконавчі елементи механізму у вигляді графіків навантажень (рис. 3,4 ), 

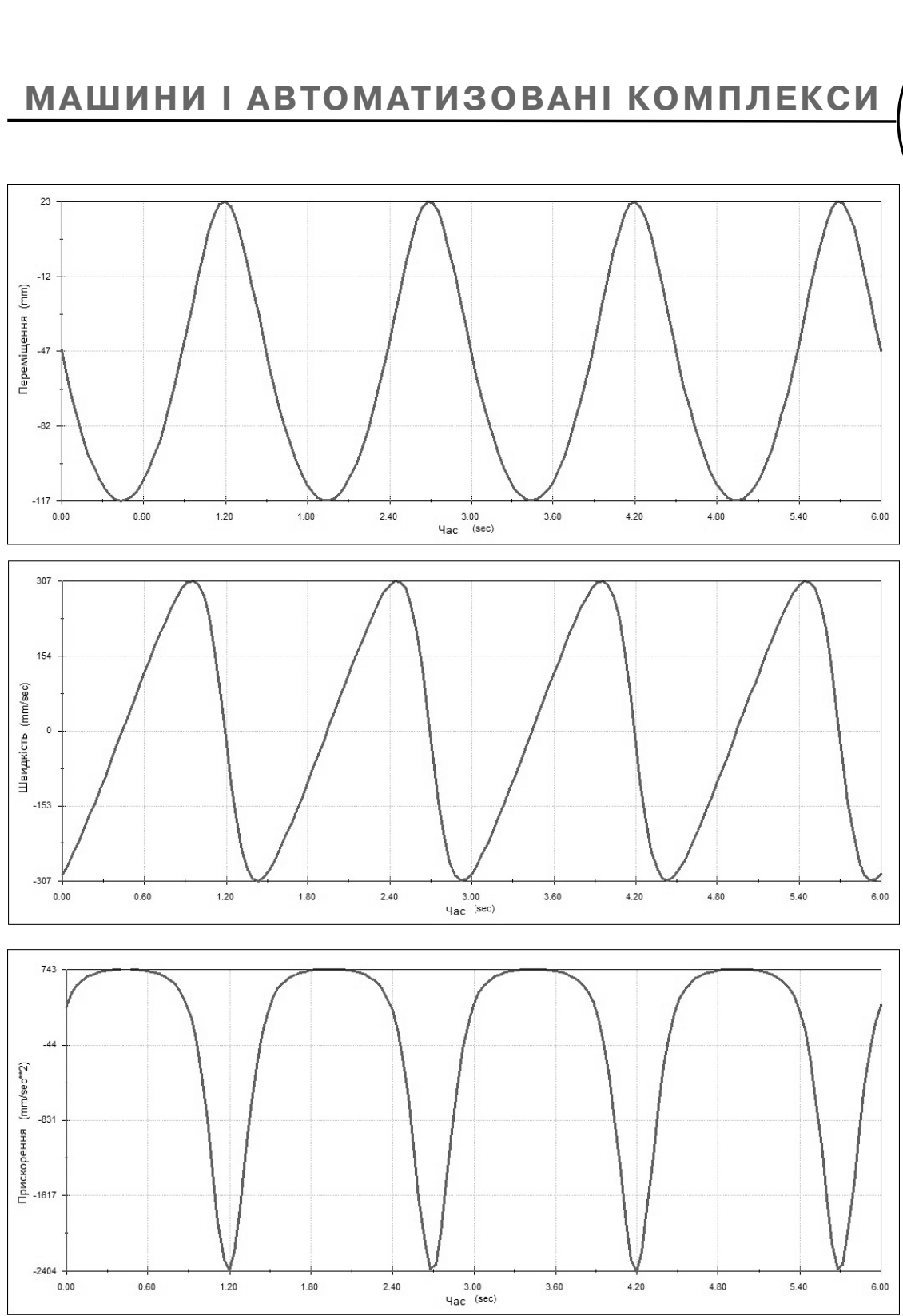

Рис. 1. Графіки переміщення, швидкості та прискорення ножа залежно від часу

що змінюються залежно від кута повороту головного валу (рис. 5). Це дає змогу змоделювати робочий цикл машинного технологічногопроцесу.

Використавши програмне забезпечення Mathcad та SolidWorks встановлені наступні величини: максимальна сумарна споживана потужність приводів ножа та балки притиску
$\mathrm{W} \leq 2$ кВт, при заданих навантаженнях під час різання $\mathrm{F}_{\text {p.max }} \leq$ $\leq 3200$ Н та зусилля балки притиску $F_{\text {пр.max }} \leq 4700 \mathrm{H}$.

Структурна схема механізму подана на рис. 6. Наскрізна нумерація рухомих ланок позначена арабськими цифрами, а кінематичні пари великими літерами латинського алфавіту. 

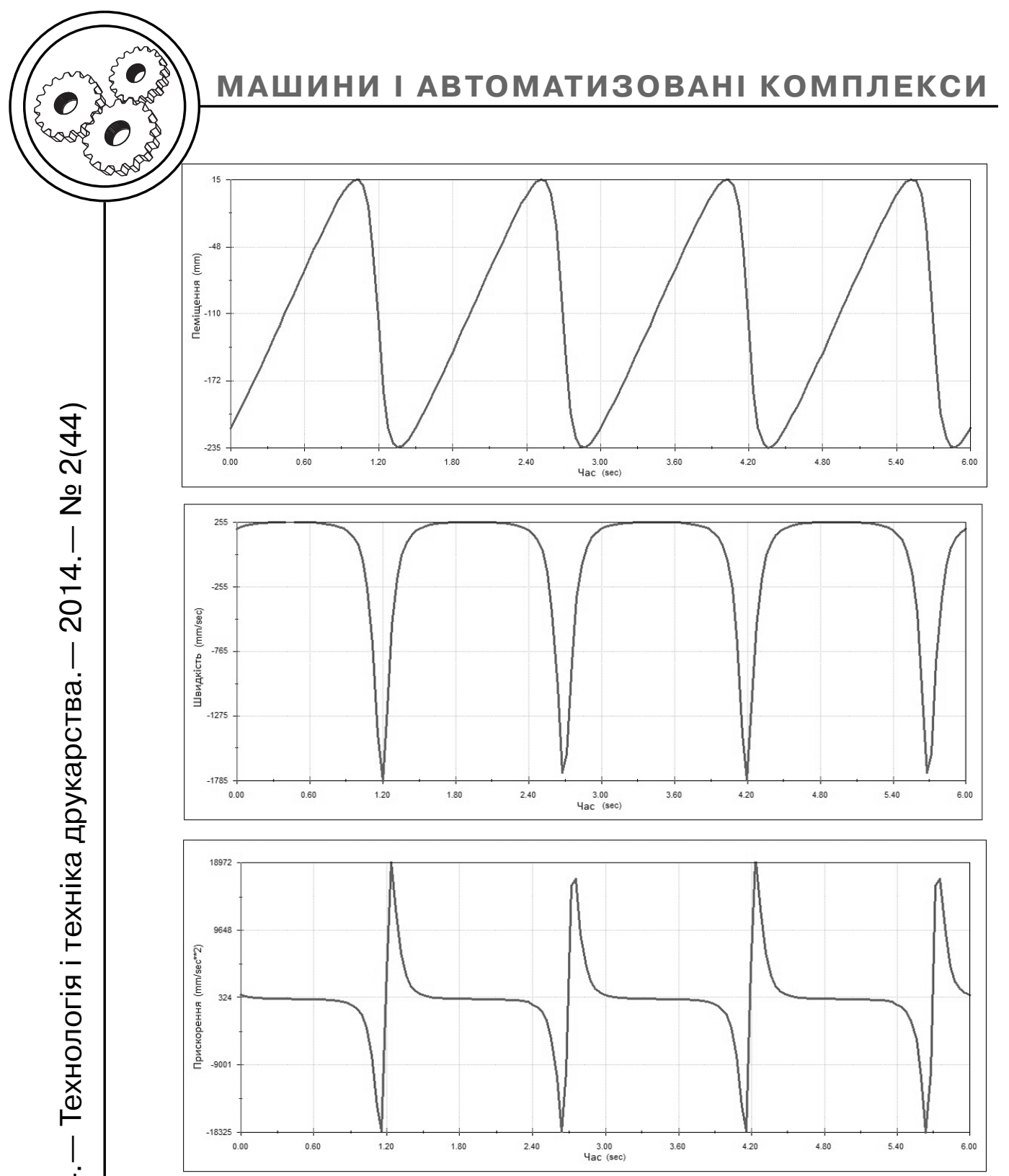

Рис. 2. Графіки переміщення, швидкості та прискорення балки головного притиску залежно від часу

Загалом механізм нараховує дванадцять рухомих ланок. Таким чином 1 та 6 кривошипи; 2, 4, 7, 9 - повзуни; 3, 5, 8, 10 - куліси. Рухомі ланки 11 та 12 працюють у якості балки притиску та ножотримача відповідно.

Механізм відноситься до так званих «плоских» механізмів, тому що усі рухомі ланки здійснюють свої рухи у паралельних площинах. Кінематичні пари, що сполучають ланки $€$ парами п'ятого класу (за Артоболевським).

Таким чином розрахункову ступінь вільності (рухомість) механізму необхідно визначати за формулою Чебишева: 


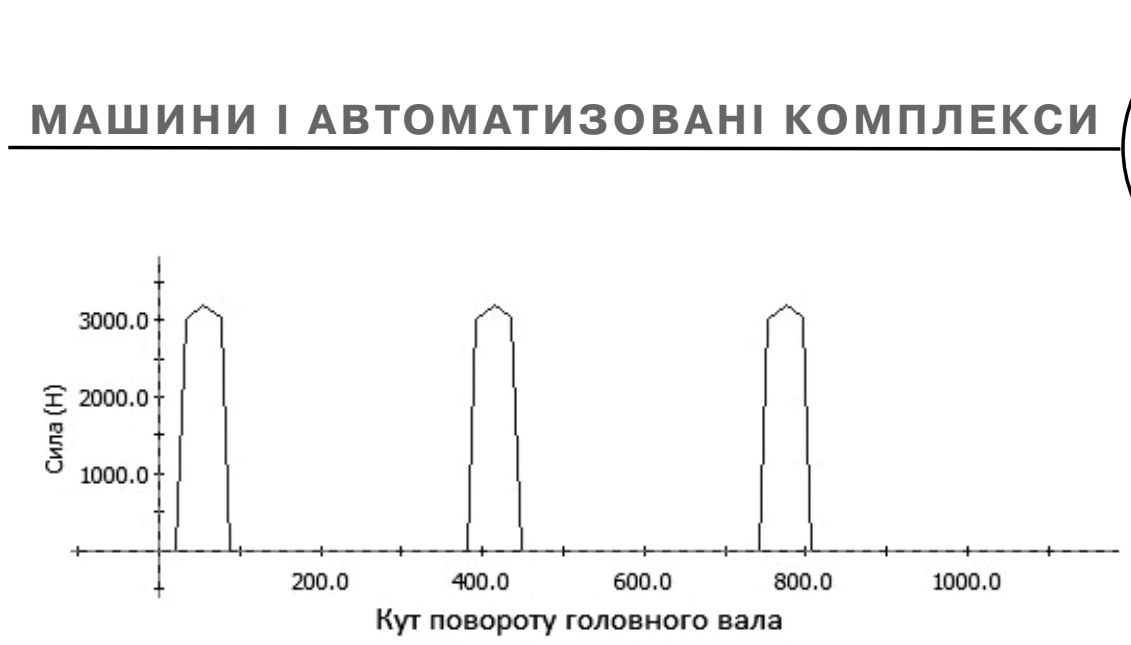

Рис. 3. Графік навантаження на ніж залежно від кута повороту головного вала

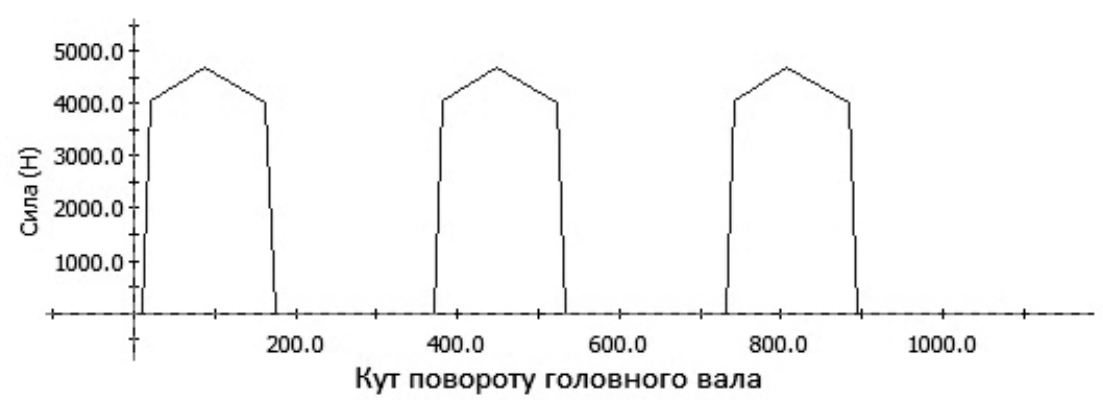

Рис. 4. Графік навантаження на балку головного притиску залежно від кута повороту головного вала

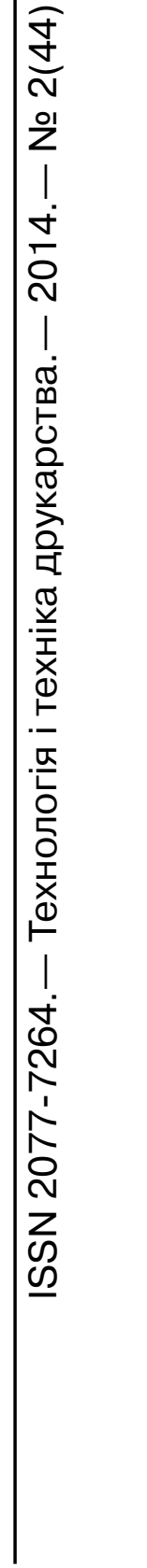

Рис. 5. Характерні кути повороту головного валу початку і кінця дії робочих елементів механізму 


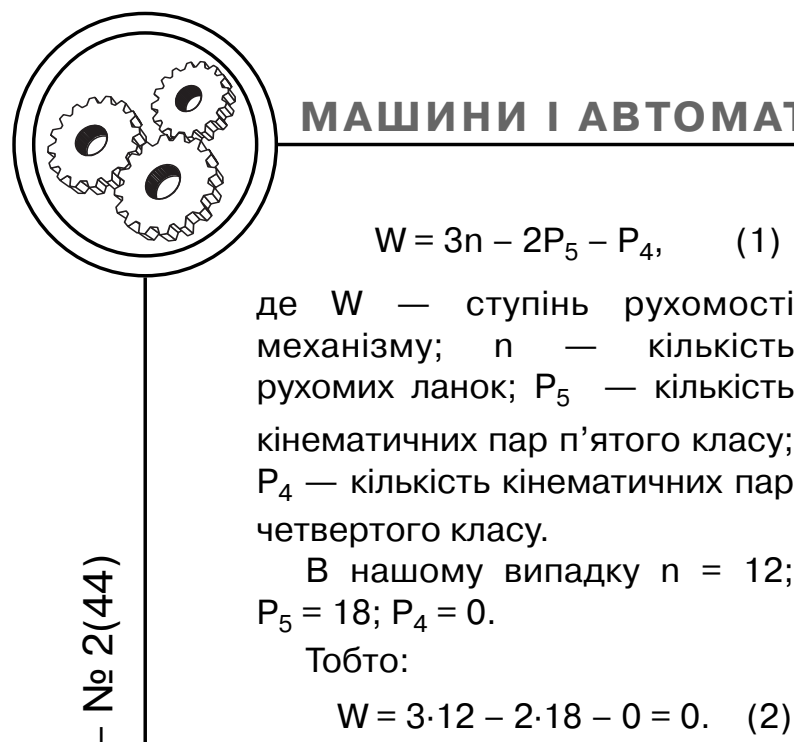

Такий результат говорить про те, що у загальному випадку, коли ланки 5 та 10, а також 11 та 12 не паралельні і не рівні за довжиною між собою механізм не $є$ рухомою системою.

У даному випадку, коли ці ланки паралельні і рівні за довжиною цей механізм може повноцінно працювати і виконувати потрібні траєкторії pyxy.

3 точки зору структурного аналізу ланка 11 (або 12) $€$ «зайвою», а кінематичні пари, якими вона з'єднується із сусідніми ланками являють

собою так звані «пасивні в'язі».

Якщо «звільнити» механізм від цих в'язів та «зайвої» ланки, механізм перетворюється в рухому систему із ступенем вільності, що дорівнює одиниці.

Тоді, якщо початковий механізм складається із стояка та ланки 1 (кривошип), які сполучені обертальною парою п'ятого класу $\mathrm{O}_{1}$ (шарнір), то механізм можна створити шляхом приєднання до початкового механізму структурних груп Ассура, які утворюються ланками та кінематичними парами (рис. 7).

Всі структурні групи відносяться до другого класу та другого порядку. Таким чином механізм, що розглядається $€$ механізмом другого класу.

Структурна формула складання механізму має вигляд:

$$
\begin{aligned}
(0,1) \leftarrow(2,3) \leftarrow(4,5) \leftarrow(10,11) \leftarrow \\
\leftarrow(8,9) \leftarrow(6,7)
\end{aligned}
$$

Початковий механізм складається з ланок 0 та 1 , до якого

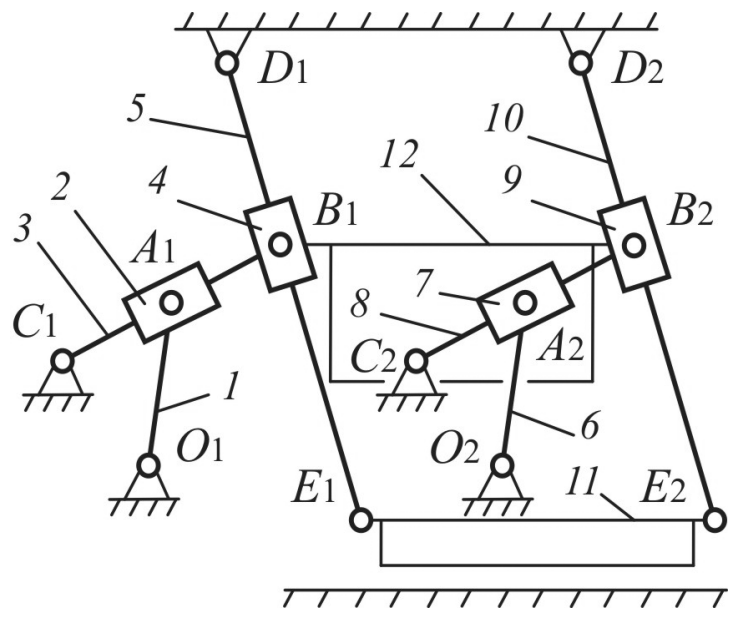

Рис. 6. Структурна схема механізму 
приєднуються структурні групи (цифри в дужках - номера ланок, що входять до складу груп). Щодо так званої «зайвої» ланки, то вона $є$ ножотримачем і надає механізму корисні властивості, тобто забезпечує виконання двох технологічних операцій одночасно.

Щоб уникнути небезпеки заклинювання механізму під час роботи слід одну з двох кінематичних пар, що з'єднує «зайву» ланку з механізмом, зробити п'ятого класу, а другу четвертого класу. У такому випадку ступінь вільності механізму буде дорівнювати одиниці. Тобто механізм стає «раціональним» без «зайвої» ланки.

\section{Висновки}

Забезпечення заданої траєкторією руху елементів механізму сприяє зменшенню сумарної споживаної потужності привода, а кривошипно-кулісний привод дозволяє балці притиску та ножу одночасно виконувати машинну технологічну операцію під час транспортування.

Результати досліджень, що відображені графічно дали можливість відслідковувати швидкість руху ножа $\mathrm{V}_{\mathrm{H}}$ та головного притиску $V_{п}$, що змінюється залежно від його положення відносно осі обертання. Можна зробити висновок, що така зміна швидкості руху головного притиску не буде суттєво впливати на силу притиску, а під час різання буде забезпечувати технологічно необхідну величину затиску.

При відомих геометричних та масових параметрах ланок механізму графічно задані навантаження дають можливість змоделювати машинний технологічний процес різання та визначити максимальну споживану потужність двигуна.
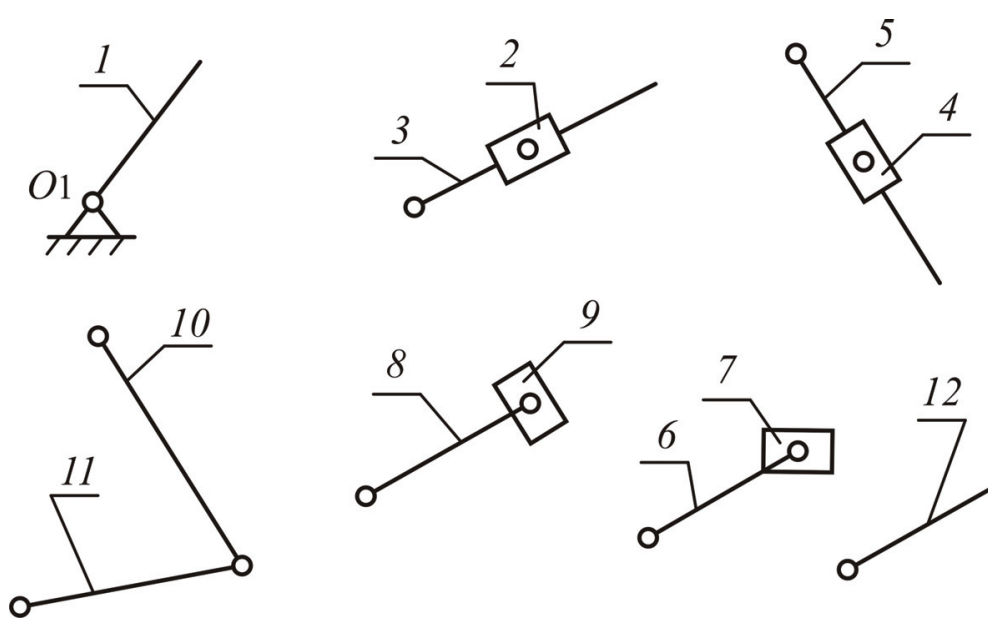

Рис. 7. Структурні групи Ассура, що утворені ланками та кінематичними парами механізму 


\section{МАШИНИ І АВТОМАТИЗОВАНІ КОМПЛЕКСИ}

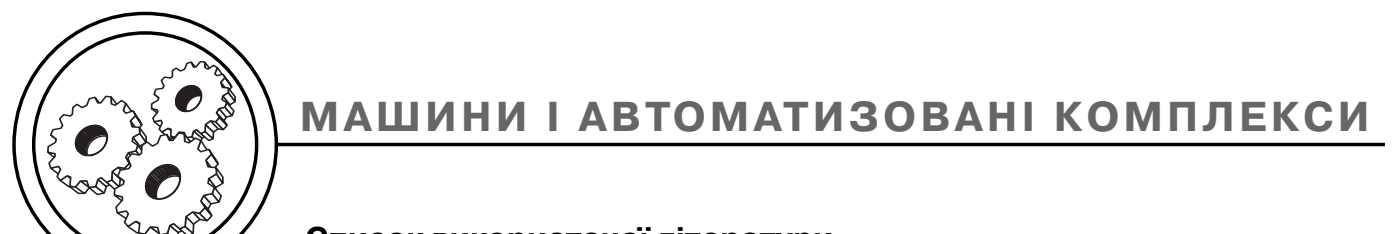

\section{Список використаної літератури}

1. Хведчин Ю. Й. Брошурувально-палітурне устаткування. Ч. 1. Брошурувальне устаткування. Підручник / Ю. Й. Хведчин. - Львів : ТеРус, 1999. - 336 c.

2. Пергамент Д. А. Брошюровочно-переплетное оборудование / Д. А. Пергамент. - М. : МПИ, 1990. - 452 с.

3. Топольницький П. В. Нові технології та пристрої для різання поліграфічних матеріалів та книжково-журнальних блоків : навч. посіб. / П. В. Топольницький, О. Б. Книш. - Львів : Афіша, 2003. - 88 с.

4. Іванко А. І. Механіка процесу обрізування книжково-журнальних блоків дисковими ножами з планетарним приводом: дис. ... канд. техн. наук: 05.05.01 / Іванко Андрій Іванович. - Київ, 2007. - 181 с.

5. Іванко А. І. Вплив технологічних процесів різання аркушевих матеріалів на якісні характеристики продукції / А. І. Іванко, К. О. Чепурна К. О. Махинич // Технологія і техніка друкарства. - Київ. - 2013. - Вип. 1(39). - C. 28-39.

6. Іванко А. І. Конструкція пристрою для безупинного обрізування аркушевого матеріалу в потокових лініях / А. І. Іванко, Р. В. Маржієвський // Технологія і техніка друкарства. - Київ. - 2012. - Вип. 3(37). С. $109-113$.

7. Пат. України на корисну модель № 80303. B26D1/00. Пристрій для безупинного обрізування аркушевого матеріалу в потокових лініях / А. І. Іванко, Р. В. Маржієвський. - Заявл. 12.11.2012; Опубл. 27.05.2013. Бюл. № 10, 2013. - 4 с.

8. Артоболевский И. И. Теория механизмов и машин : Учеб. для вузов / И. И. Артоболевский. - 4-е изд., перераб. и доп. - М. : Наука. Гл. ред. физ.-мат. лит., 1988. - 640 с.

\section{References}

1. Khvedchyn Iu. I. Broshuruvalno-paliturne ustatkuvannia. Ch. 1. Broshuruvalne ustatkuvannia. Pidruchnyk / lu. I. Khvedchyn. - Lviv : TeRus, 1999. - $336 \mathrm{c}$.

2. Pergament D. A. Broshjurovochno-perepletnoe oborudovanie / D. A. Pergament. - M. : MPI, 1990. - $452 \mathrm{~s}$.

3. Topolnytskyi P. V. Novi tekhnolohii ta prystroi dlia rizannia polihrafichnykh materialiv ta knyzhkovo-zhurnalnykh blokiv : navch. posib. / P. V. Topolnytskyi, O. B. Knysh. - Lviv : Afisha, 2003. - 88 s.

4. Ivanko A. I. Mekhanika protsesu obrizuvannia knyzhkovo-zhurnalnykh blokiv dyskovymy nozhamy z planetarnym pryvodom: dys. ... kand. tekhn. nauk: 05.05.01 / Ivanko Andrii Ivanovych. - Kyiv, 2007. - $181 \mathrm{~s}$

5. Ivanko A. I. Vplyv tekhnolohichnykh protsesiv rizannia arkushevykh materialiv na yakisni kharakterystyky produktsii / A. I. Ivanko, K. O. Chepurna, K. O. Makhynych // Tekhnolohiia i tekhnika drukarstva. - Kyiv. - 2013. Vyp. 1(39). - S. 28-39.

6. Ivanko A. I. Konstruktsiia prystroiu dlia bezupynnoho obrizuvannia arkushevoho materialu v potokovykh liniiakh / A. I. Ivanko, R. V. Marzhiievskyi // Tekhnolohiia i tekhnika drukarstva. - Kyiv. - 2012. - Vyp. 3(37). S. $109-113$.

7. Pat. Ukrainy na korysnu model № 80303. V26D1/00. Prystrii dlia bezupynnoho obrizuvannia arkushevoho materialu v potokovykh liniiakh / A. I. Ivanko, R. V. Marzhiievskyi. - Zaiavl. 12.11.2012; Opubl. 27.05.2013. - Biul. № 10, 2013. $-4 \mathrm{~s}$. 
8. Artobolevskij I. I. Teorija mehanizmov i mashin : Ucheb. dlja vuzov / I. I. Artobolevskij. - 4-e izd., pererab. i dop. - M. : Nauka. Gl. red. fiz.-mat. lit., 1988. $-640 \mathrm{~s}$.

В статье представлены результаты предварительных кинематических и динамических расчетов конструкции устройства безвыстойной обрезки листового материала.

Ключевые слова: устройство для обрезки листового материала, кривошипно-кулисный механизм, кинематический анализ, динамический анализ, силовой расчет.

In the article is described the kinematics and dynamic calculations of construction device of the nonstop trimming of sheet material.

Keywords: device for trimming sheet material, crank-rocker mechanism, kinematic analysis, dynamic analysis, power calculation.

$$
\begin{array}{r}
\text { Рецензент - Ю. О. Шостачук, к.т.н., } \\
\text { доцент, НТУУ «КПІ» }
\end{array}
$$

